\title{
Reform of Embedded System Course Based on CDIO Education Mode
}

\author{
Chengbing Wei, Bin Xu, Jiechun Dong, Yingchao Zhou \\ School of Electronic Information \\ Qingdao University \\ Qingdao, zip 266003, China
}

\begin{abstract}
The specific goal of the CDIO teaching model is to combine personal, social, and systemic manufacturing techniques to fit all areas of engineering. In order to improve students' ability to use embedded system technology in a comprehensive manner, a teaching scheme that integrates the theory of embedded systems with the CDIO teaching model is proposed. The author proposes to strengthen professional basic education and pay attention to engineering practice; strengthen the coordination and communication skills of college students and the cultivation of teamwork spirit; cultivate comprehensive suggestions for innovation.
\end{abstract}

Keywords-embedded system; curriculum; practical teaching; innovation ability;

\section{INTRODUCTION}

The CDIO engineering education model is the latest result of the international engineering education reform in recent years. Since 2000, the multinational research of MIT and the Swedish Royal Institute of Technology has received a huge grant of nearly US\$20 million from the Knut and Alice Wallenberg Foundation. After four years of exploration and research, the concept of CDIO Engineering Education was established.

CDIO stands for Conceive, Design, Implementation, and Operate. It takes the life cycle of product development and product operation as the carrier, allowing students to learn the project in an active, practical and organic way. The CDIO syllabus divides the ability of engineering graduates into four levels: engineering basic knowledge, individual ability, interpersonal team ability, and engineering system capability. The outline requires students to achieve the desired goals at these four levels through comprehensive training. The concept of CDIO not only inherited and developed the concept of engineering education reform in Europe and America for more than 20 years. More importantly, it has systematically proposed standards for operability training, comprehensive implementation, and inspection and evaluation. In 2005, the Swedish National Agency for Higher Education evaluated 100 engineering degree programs in the country. The results show that the new standard is wider than the original standard and is more conducive to improving quality. What is particularly important is that the new standards provide the basis for the systematic development of engineering education. Students who have been trained in the
CDIO model so far are very popular with society and businesses $^{[1-5]}$.

\section{THE PROBLEM OF ENGINEERING EDUCATION}

The current engineering education model in China is born out of the professional education of the former Soviet Union. This model has two characteristics that are incompatible with the requirements of modern industrial practice: one is the professional oriented training that meets the requirements of the planned economy, and the other is the disconnect between the cultivation of students' technical skill development and the requirements of modern industry. Professional orientation leads to narrow students' knowledge and graduates lack of competitiveness. Discipline education does not fully develop students' independence, creativity, learning ability and adaptability. More importantly, subject education is out of touch with industrial practice. Students have almost no development in the team spirit, communication ability, multidiscipline, and large-scale system control ability that relies on to survive and grows in modern industrial production.

The era of economic globalization and knowledge economy has come. How to deal with this trend of development is a core issue that concerns all countries and all fields in the world. The development of China's engineering education towards internationalization is precisely in accordance with the economic globalization and is the inevitable outcome of the process of world economic integration. The urgent task of China's higher engineering education is to try(In Chinese) engineers who are in line with international standards as quickly as possible. However, there are still many problems in the practice of engineering education in China, such as focusing on theory and despising practice, emphasizing individual academic ability and ignoring the spirit of teamwork, emphasizing knowledge learning and ignoring the issues of pioneering and innovative training. Contrary to the international consensus on engineers' requirements, such as the requirements of Boeing, $\mathrm{ABET}$ EC2000, and CAEB, it is easy to find that China's engineering education obviously lacks personal development ability, interpersonal communication ability and system design ability. The training and these abilities are exactly what a successful international company needs for a qualified engineer.

According to a report released by the McKinsey Global Institute in October 2010, less than $10 \%$ of the approximately 600,000 engineering and technical personnel graduated from 
China in 2010 are suitable for working in international companies. The reason is education system biased in theory, and Chinese students have virtually no practical training for projects and team work, compared with European and North American students who solve practical problems in teams. Therefore, we face enormous challenges. In order to meet the requirements of engineers for future development, we must carry out engineering education reforms and carry out comprehensive and thorough reforms of existing training programs $^{[6-8]}$.

\section{THE GOAL}

The aim of the reform is to focus on cultivating students' systematic engineering skills, especially the project organization, aiming at the emphasis on theoretical training and application in the practice of engineering education in our class. So, our specific goal is to make students have such abilities as list: - Strong project development, design and construction capabilities; • Strong innovative ability; • Strong teamwork and leadership skills; • Strong communication skills; - Strong Chinese and English language skills.

These five goals complement each other and are independent of each other.

\section{Course Status Analysis}

The orientation of the electronic engineering major requires students to have a solid foundation in electronics, computers, and communications, as well as cross-discipline research and development capabilities, and capable of employing highlycompetitive applied talents in various fields. The main objectives of the curriculum reform of embedded systems are listed below: (1) To develop students' hardware and software development experiments for embedded systems based on experimental development conditions. Let students be familiar with the development environment, and understand the embedded system development process. (2) On the basis of the first level, students should be trained according to the existing experimental platform, be familiar with the platform's diverse programming functions. Through the whole process, it can improve students' programming ability. (3) Through the whole process, the goal is to develop students' ability of system design, to make self-design according to the existing platform, and to give full play to the students' creativity and research ability. (4) While the students mastering theoretical knowledge fully, teachers must also cultivate to students a certain degree of application ability and thinking innovation ability, which helps them to explore the curriculum independently. (5) Through the whole course, the goal is to promote students' interpretation of knowledge, to promote the academic development of teachers, and to strengthen the cultivation of students' comprehensive abilities.

The first stage: the embedded system teaching contents are mainly laboratory embedded platform and development manual. The emphasis of the teaching content is adjusted accordingly, and the content of the hardware equipment system which is widely used and easy to be used is properly added to increase the students' understanding of the application system and the development content. Finding content that students are interested in can promote their active learning. At the same time, teachers can reduce the proportion of old knowledge, which is no more used in the industry. The second stage: after understanding the content of the course, teachers can group students, and emphasize the discussion and cooperation within the group. On the basis of independent thinking, students can solve problems jointly through group cooperation and mutual communication. In addition, by pre selecting group project assignments, students can learn to complete project assignments while learning. If time is too hasty, students will not be able to complete project assignments on time. The third stage: the learning teams are working under the leadership of the team leader to coordinate the task of autonomous learning. In the absence of teacher supervision, students can have a freer and relaxed learning environment. The fourth stage: in the course of the weekly course teaching, teachers should communicate with each group to learn the results, inspire the ideas and ideas of the group, discuss the difficulties in the study and share the excellent results of the study among the groups. In the course of teaching, teachers can draw out 15 minutes per week, report the theoretical knowledge by each group, discuss and communicate with the rest of the group, listen to the teachers and make comments and guidance. Case teaching runs through it. Through group case analysis, students can get more content in the short term and better understand the whole embedded system. The fifth stage is to select excellent teams and demonstrate and explain them. The other students can learn the excellence and spirit of the excellent group. This can promote the improvement of the design for every student. After practice teaching, the teaching quality of teachers can usually achieve the desired effect. Students not only mastered the knowledge taught by teachers, but also expanded their horizons and widths. This can cultivate autonomous learning attitude and technical skills. At the same time, their practical ability is also greatly enhanced.

\section{AsSESSMENT METHOD REFORM}

Check the team project assignments and grade them. There are total three grading levels: (1) Excellent standard - While realizing functions, system performance and interactivity are good; (2) Good standard - Achieve function fully, system performance in general; (3) Qualify standard-- is to achieve the function partially. At the same time, attendance, questioning and discussion can be used as the main basis for student achievement. By assessing students' learning situation, we can compare the past teaching status with the current achievements. Through the analysis of learning results, it can be served as an important basis for students' future teaching improvement direction.

\section{CONCLUSION}

With the progress of the times, the improvement of teaching conditions and the enhancement of teachers' ability, the requirements of company to the students for their practical ability are getting higher and higher. The existing teaching conditions not only meet the requirements of theoretical teaching, but also meet the needs of practical teaching. Practical teaching should teach students in accordance with their aptitude, conduct certain guidance according to students' 
characteristics and interests, and be open to students. The results of the course show that the curriculum reform plan can improve students' practical skills and teachers' thinking and changes in curriculum teaching. This will help improve the quality of classroom teaching.

\section{REFERENCES}

[1] Crawley, E. F., Malmqvist, J., Lucas, W. A., \& Brodeur, D. R. (2011). The CDIO Syllabus v2.0: An Updated Statement of Goals for Engineering Education", In proceedings of the 7th Intl. CDIO conference. In University of Demark, Copenhagen.

[2] Hussmann, Peter Munkebo, Proc. of the 7th Int'l CDIO Conference, Technical University of Denmark, Copenhagen, June 20 - 23, 2011

[3] Edwardf. Crawley, Johan Malmqvist, soren ostluna, Doris. Brodeur (2007), Rethinking Engineering Education: The CDIO Approach, 4, 8183.

[4] Right Ning Yi, Quan Xiaolin. Exploration and Practice of Experimental Teaching Reform of Embedded System[J]. Experimental Technology and Management, 2011, 28(3):146-147,157.
[5] Crawley, E. F. (2001). The CDIO Syllabus: A statement of goals for undergraduate engineering education (Vol. 1, p. 2001). MIT CDIO Report.

[6] Zhu Minjie, Pan Zhang xin, Luo Yi. Electronic Information Engineering "Embedded System" Practical Teaching Exploration [J]. Journal of Electrical and Electronic Education, 2012,34(1):67-69. (In Chinese)

[7] Qiu Tie, Ruan Guowei, Liu Xiaoyan. Application-oriented university embedded system direction cultivation research [J]. Computer Education, 2011(4): 1-4. (In Chinese)

[8] ZHENG Chunlong, SHAO Hongyan. Construction and implementation of practical teaching system in colleges and universities aiming at the cultivation of innovative practical ability [J]. China Higher Education Research, 2007, (4): 85-86. (In Chinese)

[9] Sun Wenbin. Reform and Practice of Open Innovation Experiment Teaching[J]. Laboratory Research and Exploration, 2006, 25(2): 148151. (In Chinese)

[10] Zhu Minjie, Pan Zhang xin, Luo Yi. Electronic Information Engineering "Embedded System" Practical Teaching Exploration [J]. Journal of Electrical and Electronic Education, 2012,34(1):67-69. (In Chinese) 